\title{
The Relationship between Socio-Economic Status, General Language Learning Outcome, and Beliefs about Language Learning
}

\author{
Mohsen Ghasemi Ariani ${ }^{1,2} \&$ Narjes Ghafournia ${ }^{2}$ \\ ${ }^{1}$ Department of English, Khorasan e Razavi Science and Research Branch, Islamic Azad University, Neyshabur, \\ Iran \\ ${ }^{2}$ Department of English, Neyshabur Branch, Islamic Azad University, Neyshabur, Iran \\ Correspondence: Narjes Ghafournia, Department of English, Neyshabur Branch, Islamic Azad University, \\ Neyshabur, Iran. Tel: 98-915-313-0060. E-mail: narjesghafournia@yahoo.com; na.ghafournia@gmail.com
}

Received: August 8, 2015 Accepted: September 11, 2015 Online Published: January 25, 2016

doi:10.5539/ies.v9n2p89 URL: http://dx.doi.org/10.5539/ies.v9n2p89

\begin{abstract}
The objective of this study is to explore the probable relationship between Iranian students' socioeconomic status, general language learning outcome, and their beliefs about language learning. To this end, 350 postgraduate students, doing English for specific courses at Islamic Azad University of Neyshabur participated in this study. They were grouped in terms of their socioeconomic status. They answered a questionnaire in which they indicated their beliefs about language learning in different contexts of language use. Besides, a general language test of proficiency (a Practice test of a TOEFL Test) was administered to all the participants to homogenize them in terms of general language proficiency or general language learning outcome. The quantitative data were subjected to a set of parametric statistical analyses, including descriptive statistics and factor analysis. The findings manifested a positive relationship between the students' economic status and general language learning outcome. Besides, the findings manifested a significant relationship between the participants' language learning outcome and their beliefs about language learning. The findings suggest if language instructors are equipped with the necessary information to assist language learners in coping with their negative beliefs, the process of language learning is not only accelerated, but also probable measurement errors may decrease.
\end{abstract}

Keywords: language-learning belief, socioeconomic status, general language learning outcome, measurement error

\section{Introduction}

The idea that students' beliefs about foreign language learning have an influence on their success or failure in achieving competence in a foreign language is well documented (Horwitz, 1988; Jernigan, 2001; Kern, 1995; Miele, 1982; Rifkin, 2000; Strevens, 1978). The major findings of the above-mentioned studies indicate that individuals' positive or negative beliefs and perceptions about foreign language learning have a similarly positive or negative effect on their success. Mantle-Bromley (1995), for example, argued that positive beliefs about foreign language learning in relation to a positive learning environment such as trust-building between teachers and students facilitate foreign language learning. Horwitz (1987) argued that students' beliefs about foreign language learning affect the types of learning strategies that these students choose. Mirza (2001) in a study on the relationship between socioeconomic status and learning outcomes found that socioeconomic status of students has fairly significant effect on their learning outcomes. In fact, socioeconomic characteristics of students, which are examined to clarify students' learning outcomes, make the most common factor in sociology of education (Sirin, 2005). Mattheoudakis and Alexiou (2009) found that there are some advantages for the students from superior socioeconomic status over the students from socioeconomically advanced background. The students who relate to high social and economic classes are usually successful because they have open opportunities that are necessary to accelerate the learning process whereas people who belong to lower socioeconomic statuses deal with lack of resources (Akhtar \& Niazi, 2011). Some other research studies showed that students from high socio economic status group earn higher test scores and better grades than the children from low group (Knapp \& Shields, 1990; Reed \& Sautter, 1990). The socioeconomic status of students is most commonly determined by combining educational level, occupational status, and income level (Jeynes, 2002). Hamid (2011) scrutinized the relationships between students' socioeconomic status and their learning outcomes. 
The results showed that there were patterned relationships between the students' socioeconomic characteristics and their learning outcomes in English. Students who had higher levels of social and economic status were more likely to obtain higher scores on the proficiency test as well as higher grades in English. According to Babikkoi and Binti-Abdul-Razak (2014), socioeconomic status of learners is a fundamental factor that may contribute to English language learning outcomes. This is particularly because they are encouraged to learn. This is often not similar to situation in the low socioeconomic status, where students are not motivated to study.

Therefore, investigating the learners' beliefs in the context of their varying characteristics such as socioeconomic status and what effect such a variable can have on a student's learning outcome is a main component of educational progress. As students bring their own attitudes, interests, and skills to the learning situation, and these beliefs and attitudes affect the opportunities for success for every student, socioeconomic status and beliefs about language learning are strong factors that teachers should take into consideration for educational progresses. Awareness of students' beliefs would result in students' working together with the same feelings and efforts. Understanding students' beliefs and feelings in language learning can lead teachers to adopt new teaching techniques that are fair and effective. In fact, knowledge of students' background and beliefs helps teachers examine their instructional and lesson plans and become sensitive to providing better learning and teaching conditions.

\section{Review of the Related Literature}

According to Ogunshola and Adewale (2012), the relation of society, education and economy are so crucial that training of a student is dependent upon the three factors. The learning outcome of the student has relationship with the student's social class, where not only the socioeconomic status plays its role but educational level also contributes its part. The groundwork for the research into students' beliefs was laid for the most part in the 1970s and 1980s, with studies that had emphasis in validating and defining key concepts, in which further studies could take place. Work like Bartley's (1970) article correlated belief with attrition, Gardner's (1985) exploration of the belief-dependent socioeconomic model of language learning and learners' attitudes (Horwitz, 1988) largely emphasized the task of operationalizing the target construct, crafting a survey from its primary identified components, and validated that survey. Important instruments such as the Foreign Language Attitude Scale (FLAS) (Bartley, 1970), the Attitude/Motivation Test Battery (AMTB) (Gardner, 1985), and the Beliefs about Language Learning Inventory (BALLI) (Horwitz, 1988) were the tools that were created, validated, or used in those studies. Other texts of the time that focused on individual student differences, notably Spolsky (1989) and Skehan (1989) also depended on these instruments to define these concepts. Some researchers showed medium to strong relationship between students' learning outcomes and socioeconomic status. That is, successful students belong to high social and economic classes and unsuccessful students belong to low socioeconomic status (Barry, 2005; Ewijk \& Sleegers, 2010; Sirin, 2005).The socioeconomic status of a student is most commonly determined by combining educational level, occupational status, and income level (Jeynes, 2002). Studies have repeatedly found that socioeconomic status affect students' outcomes (Baharudin \& Luster, 1998; Eamon 200; Jeynes 2002; Majoribanks, 1996; Mecneal 2001; Seyfried, 1998). Some other studies with the trait/student orientation have remained at the descriptive level, refraining from linking students' beliefs to outcomes. For instance, authors of studies using both structural equation modeling (Csizér \& Dörnyei, 2005) and qualitative interviews (Graham, 2006) have provided detailed descriptions of motivation (in the former case) and self-efficacy (in the latter case). These researchers did suggest interestingly that the positive academic outcomes were expected, given the effort implied in highly motivated students or students with high self-efficacy. Descriptions of students' beliefs have also been common in the field, often focusing on specific aspects of language learning. According to Rad (2010) and Dörnyei (2005), beliefs and attitudes of learners about foreign languages are fundamental and in the focus of educational progress. Altan (2012) believed that at least some knowledge of English is urgent to make progress in life and work because it provides individuals with high social status and job opportunities. In fact, the seemingly stronger link between motivational factors, learners' beliefs, and socioeconomic status might be due to the highly segregated nature of education and the deep socioeconomic division among the investigated learners (Lamb, 2012).

Therefore, the purpose of this study is to explore the probable relationship between Iranian students' socioeconomic status, general language learning outcome, and their beliefs about language learning. Understanding the role of learners' goals, self-related beliefs and self-regulatory processes is essential before effective instructional programs for learners studying in different social contexts can be designed and implemented (Kormos \& Kiddle, 2013). Socioeconomic status, however, does not only affect language learning outcomes but also has an influence on motivation to learn, self-regulation, and students' self-related beliefs (Fan, 2011). For Vellymalay (2012), social and economic factors provide educational resources for 
students and have the greatest impact on their learning outcomes. Social factors also motivate and help students to have better learning opportunities and educational conditions. The present study explores the probable relationship between Iranian students' socioeconomic status, general language learning outcome, and their beliefs about language learning. Concerning the mentioned points, the research questions of this study are formulated as the following:

1) Is there any relationship between socioeconomic status and general language learning outcomes of Iranian students?

2) Is there any relationship between general language learning outcomes of Iranian students and their socioeconomic status?

To probe the research questions, the method as well as the findings is discussed in the following sections.

\section{Methodology}

\subsection{Participants}

The participants for this study were 350 Iranian postgraduate students of Management, doing English courses at Islamic Azad University in Neyshabur. They were in the 23-45 age range, forming a proportion of $58.28 \%$ males and $41.72 \%$ females. Participants were distributed across five social and economic groups. The majority of the students belonged to middle class (30.86\%) and lower middle class (30\%). $20 \%$ of the students were upper middle class, $12 \%$ were lower class, and $7.14 \%$ belonged to the upper class. In fact, $24.85 \%$ of the students were unemployed and $75.15 \%$ were employed.

\subsection{Instrument}

The instrument was developed in two stages. In the first stage, many items were derived from existing instruments such as the Belief Inventory, developed by Horwitz (BALLI, 1988). In the second stage, in order to elicit some particular information about the participants' social and economic data, a Socioeconomic Status (SES) Questionnaire was used. In fact, it was constructed and reviewed by different experts of psychology, sociology, and languages, who give their feedback on the content.

\subsubsection{The Beliefs about Language Learning Inventory (BALLI)}

The questionnaire derived from Horwitz' (1987) 35-item Beliefs about Language Learning Inventory (BALLI) was utilized for this study. The questionnaire is a five-point Likert scale, ranging from 1 (strongly disagree) to 5 (strongly agree) for 33 items. The remaining two items have a different scale and different response options. They measure the level of difficulty of English (item 4) and the requisite time to learn a new language (item 15). The participants had to rate the statements on their beliefs about language learning. Beliefs about Language Learning Inventory (BALLI) explores five logical areas, i.e. beliefs dealing with foreign language aptitude (items 1, 2, 5, 6, 10,11, 16, 19, 30, 33, 35), learning and communication strategies (item 9, 13, 14, 17, 18, 21, 22, 26 ), the nature of language learning (items $8,12,17,23,27,28$ ), the difficulty involved in learning (items 3,4 , $15,25,34$ ), and motivations and expectations (items $20,24,29,31,32$ ). To remove probable ambiguities, the BALLI questionnaire was translated into Persian, the participants' mother tongue. Before the actual administrations, the BALLI and socioeconomic status questionnaire were checked by some professors on psychology and language, who gave useful feedback on the content of the questionnaire as well as the clarity of the items. Then, BALLI questionnaire was piloted on a sample of about 40 students, whose feedback improved the items.

\subsubsection{SES Questionnaire}

"Socioeconomic Status Scale (SES) Questionnaire" was used to identify the Socioeconomic Status (SES) of the sampled students. It was reviewed by different experts of Psychology, Sociology, and Language, who give their feedback on the content. In the light of the experts' opinions, the instruments were finalized.

\subsubsection{TOFEL Test}

All the participants took a general language proficiency test of TOEFL to homogenize them in terms of language proficiency. For the purpose of this study, only the students at the intermediate proficiency level were selected. Thus, from the initial sample, consisting of 500 participants, only 350 participants, whose score was between \pm one standard deviation from the mean were recruited for the purpose of the study. It piloted on a sample of about 40 students to improve the items. The reliability analysis showed an overall Alpha Cronbach's value of .817, which was acceptable and high. 


\subsection{Procedure}

To remove the probable ambiguities, the BALLI questionnaire was translated into Persian, the participants' mother tongue. Before the actual administrations, the BALLI and SES questionnaire were checked by some professors on psychology and language, who gave useful feedback on the content of the questionnaire as well as the clarity of the items. Then, BALLI piloted on a sample of about 40 students, whose feedback improved the items. Besides, a general language test of proficiency (a practice test of a TOEFL Test) was administered to all the participants to homogenize them in terms of language proficiency. Due to practical problems, only the reading, grammar and written expression sections were administered to the participants. A one-way ANOVA was conducted to determine the relationship between socioeconomic status and beliefs about language learning

\subsection{Data Analysis}

The statistical procedures used in the study were Cronbach alpha formula, descriptive statistics, a principal component analysis, and one-way analysis of variance.

\section{Result and Discussion}

The purpose of the current study was to determine to what extent socioeconomic status, general language learning outcome, and beliefs about language learning are related. The current data highlight the importance of socioeconomic status as a strong predictor of students' outcomes and principal variables of beliefs about language learning. To scrutinize the relationship between these factors, the statistical procedures were used.

\subsection{Latent Variables Explored by the BALLI}

In order to enhance the reliability of the results, a principal component analysis of the data was carried out. Table 1 summarizes the results of the principal component analysis of the data, gathered in this study as well as Horwitz's (1987) separation of items under her five themes.

Table 1. Horwitz's (1987) separation of items

Beliefs $\quad$ Loading

Factor 1. Foreign language aptitude (Cronbach's alpha $=.80$ )

1. It is easier for children than adults to learn a foreign language

2. Some people have a special ability for learning foreign languages.

5. I believe that I will learn to speak English very well

6. People from my country are good at learning foreign languages.

10. It is easier for someone who already speaks a foreign language to learn another one. 0.57

30. People who speak more than one language are very intelligent 0.55

33. Everyone can learn to speak a foreign language. $\quad 0.55$

35. Language learning involves a lot of memorization. $\quad 0.49$

11. People who are good at mathematics or science are not good at learning foreign languages. $\quad 0.49$

16. I have a special ability for learning foreign languages $\quad 0.47$

19. Women are better than men at learning foreign languages. 0.46

Factor 2: difficulty of language learning (Cronbach's alpha $=.86$ )

3. Some languages are easier to learn than others. 0.62

4. English is a difficult/easy language. $\quad 0.60$

15. If someone spent one hour a day learning a language, how long would it take them to speak the 0.59
language very well?

25. It is easier to speak than understand a foreign language. $\quad 0.58$

34. It is easier to read and write English than to speak and understand it. $\quad 0.57$

Factor 3: Nature of language learning (Cronbach's alpha $=.84$ )

8. It is important to know about English-speaking cultures in order to speak English 
12. It is best to learn English in an English-speaking country.

0.63

17. The most important part of learning a foreign language is learning vocabulary words

23. The most important part of learning a foreign language is learning the grammar

27. Learning a foreign language is different than learning other academic subjects.

28. The most important part of learning English is learning how to translate from my native language to English or from English to my native language.

Factor 4: Learning and communication strategies (Cronbach's alpha $=.90)$

18. It is important to repeat and practice a lot.

7. It is important to speak English with an excellent pronunciation.

13. I enjoy practicing English with the native English speakers I meet.

22. If beginning students are permitted to make errors in English, it will be difficult for them to speak correctly later on.

26. It is important to practice with cassettes or tapes.

14. It is o.k. to guess if you don't know a word in English.

9. You shouldn't say anything in English until you can say it correctly.

21. I feel timid speaking English with other people

Factor 5 : Motivation and expectations (Cronbach's alpha $=.87$ )

20. People in my country feel that it is important to speak English.

24. I would like to learn English so that I can get to know native English speakers better and their cultures.

29. If I learn English very well, I will have better opportunities for a good job

31. I want to learn to speak English well.

32. I would like to have friends who speak English as a native language.

The factor, labeled foreign language aptitude, consists of 11 items, reflecting students' beliefs about language aptitude. Items $1,2,5,6,10$, and 33 are concerned with the language learning attitude of students. As well, items $35,11,16$, and 19 are concerned with disagreement about abilities in learning foreign languages. The second factor, labeled difficulty of language learning, consists of 5 items, representing students' beliefs related to the simplicity level or difficulty of language learning. The third factor, labeled the nature of language learning, comprises 6 items, reflecting students' attitudes about nature of language learning and dealing with the importance of English-speaking cultures and translation. Items 8, 12, and 28 focus on knowing the foreign culture and avoiding translation. The fourth factor, labeled learning and communication strategies, comprises 8 items, reflecting students' beliefs about practicing English language. The items under this factor emphasize the rehearsal and error avoidance strategies. The fifth factor, labeled motivation and expectations, comprises 5 items, reflecting attitudes about better opportunities.

\subsection{Comparison of Factors}

Using Principal Components Analysis (PCA), five factors were established, each corresponding to one of Horwitz's (1988) themes. Table 2 provides the summery of the results for five factors of beliefs about language learning. 
Table 2. Selected factors of BALLI questionnaire and descriptive statistics

\begin{tabular}{lcc}
\hline Item & Mean & SD \\
\hline Factor 4: Learning and communication strategies & 4.12 & 0.51 \\
Factor 5 : Motivation and expectations & 3.78 & 0.55 \\
Factor 2: Difficulty of language learning & 3.43 & 0.50 \\
Factor 3: Nature of language learning & 3.34 & 0.57 \\
Factor 1: Foreign language aptitude & 3.14 & 0.60 \\
\hline
\end{tabular}

According to the statistical analysis, factor 4 received the highest mean average among the factors. This shows that all the participants believed that rehearsal of the language and learning strategies are a very important part. Students also reported high degrees of motivation. To them, motivation is a contributing factor in language learning. Factor 2 and 3 indicates that students lean toward difficulty and the nature of language learning. It suggests that students feel that the target language is of moderate difficulty. The results for factor 1 also represent that gender in language learning does not play a crucial role.

\subsection{Relationship between Socioeconomic Status and Beliefs about Language Learning}

A one-way ANOVA was conducted to determine the relationship between socioeconomic status and beliefs about language learning. Findings showed that the socioeconomic status of the learners has some influences on the learners' beliefs. Table 3 indicates the relationship between students' beliefs about language learning at different socioeconomic status levels through using one-way ANOVA.

Table 3. One-way ANOVA for students' beliefs about language learning at different socioeconomic status levels

\begin{tabular}{lccccc}
\hline Source of Variation & Sum of Squares & $\mathrm{dF}$ & Mean Sq & $\mathrm{F}$ & P Value \\
\hline Between Groups & 3017.16 & 2 & 1511.020 & 10.012 & .000 \\
Within Groups & 26880.65 & 189 & 136.008 & & \\
Total & 29897.81 & 191 & & & \\
\hline
\end{tabular}

Table 3 shows that the difference among the mean scores of students' beliefs about language learning at different socioeconomic status levels (Upper Class, Upper Middle Class, Middle Class, Lower Middle, Class Lower Class) is significant since $\mathrm{F}_{2}=10.012, \mathrm{p}=.000$.

\subsection{Socioeconomic Status Score}

All the variables were scored and total scores were used to make different classes. The maximum scores obtained on socioeconomic status questionnaire by the students were 51 and the minimum score was 5 . According to the obtained scores, $25 \%$ of the students are unemployed and lower classes have the highest proportion of unemployment. Table 4 indicates the relationship between social class and employment.

Table 4. Relationship between social class and employment

\begin{tabular}{lcc}
\hline Class & No & Unemployed \\
\hline Upper Class & 25 & 0 \\
Upper Middle Class & 70 & 2 \\
Middle Class & 108 & 30 \\
Lower Middle Class & 105 & 25 \\
Lower Class & 42 & 30 \\
\hline
\end{tabular}

Table 4 shows that 25 students belong to upper class, 70 students are from upper middle class, 108 students are from middle class, 108 students belong to the lower middle class, and 42 are from lower class. So the very majority of the students belong to middle class and lower middle class. What is clear about the table is that 24 
percent of unemployed students belong to the lower classes. To see whether the socioeconomic status of the students and their outcomes were well distributed, related descriptive statistics (means and standard deviations) were used. As well, to study the relationship between socioeconomic status and learning outcomes of the students, the Pearson Coefficient Correlation was found suitable. Table 5 shows the means and standard deviations of socioeconomic status (SES).

Table 5. Means and standard deviations of SES

\begin{tabular}{lcc}
\hline Social Class & Mean & SD \\
\hline Upper Class & 43.16 & 5.304715 \\
Upper Middle Class & 7.954658 & 2.8204 \\
Middle Class & 22.28704 & 2.665287 \\
Lower Middle Class & 13.29524 & 2.766294 \\
Lower Class & 6.857143 & 1.37169 \\
\hline
\end{tabular}

Table 5 shows relatively large standard deviation, which indicates that socioeconomic status were spread out well. Table 6 shows the distribution of the participants in socioeconomic classes as well as the average.

Table 6. The distribution of the participants in socioeconomic classes based on SES

\begin{tabular}{lcc}
\hline Class & No & \\
\hline Upper Class & 25 & 78.76 \\
Upper Middle Class & 70 & 70.65714 \\
Middle Class & 108 & 59.23148 \\
Lower Middle Class & 105 & 51.44762 \\
Lower Class & 42 & 50.52381 \\
\hline
\end{tabular}

Table 6 indicates that upper class and upper middle class got better scores than lower class and lower middle class. Means and standard deviations were used to see whether the outcomes were well spread out. Table 7 shows the means and standard deviations of students' learning outcomes.

Table 7. Means and standard deviations of students' learning outcomes

\begin{tabular}{lcc}
\hline Class & Mean & SD \\
\hline Upper Class & 78.76 & 8.074032 \\
Upper Middle Class & 70.65714 & 6.484956 \\
Middle Class & 59.23148 & 7.341607 \\
Lower Middle Class & 51.44762 & 8.994636 \\
Lower Class & 50.52381 & 9.386649 \\
\hline
\end{tabular}

The table shows that students' learning outcomes were spread out well. To study the relationship between socioeconomic status and outcomes of the students, the Pearson coefficient correlation is used. Table 8 shows the results. 
Table 8. Correlation coefficients between students' socioeconomic status and learning outcomes

\begin{tabular}{lccc}
\hline Class & No (s) & Pearson Coefficient (r) & Critical Value \\
\hline All & 350 & -0.1 & .24 \\
Upper Class & 25 & 0.1 & .195 \\
Upper Middle Class & 70 & 0.05 & .35 \\
Middle Class & 108 & 0.03 & .23 \\
Lower Middle Class & 105 & 0.01 & .20 \\
Lower Class & 42 & -0.01 & .2 \\
\hline
\end{tabular}

The effect of socioeconomic status on education emphasizes the manner in which the socioeconomic status of students influences their beliefs, perception, and performance in the learning environment. In reviewing the table, some findings seem noteworthy. From the values listed in Table 8, it sounds that upper class students do the best. Upper middle class also appears to be keen on learning. In comparing upper and lower class, lower, middle and lower class have less interest in learning. This indicates that students who are from higher classes are interested in learning. In sum, the results suggest that upper students appear to start learning more than other groups. Looking at students in their status, the influences of social and economic classes appear to be increasingly important as lower students look less concerned with learning.

\subsection{Relationship between Socioeconomic Status and Learning Outcome}

The second research question pertains to the relationship between socioeconomic status and learning outcome. Table 8 indicates the correlation between students' outcome and their socioeconomic status, which suggest that there is a significant relationship between social classes and students' outcome. Upper class got the best scores and lower class got the lowest scores. The findings regarding the relationship between socioeconomic status and outcome have showed that upper class students were more eager to study than lower class students. It means that learning and social status are correlated. The students from upper middle class show a positive relationship with language learning and education. The performance of lower middle class students was not good, and also the performance of lower class was the worst. It can be concluded that socioeconomic status significantly affects language achievement of the students.

\section{Conclusion}

The purpose of this study was to investigate the types of beliefs of Iranian postgraduate students regarding their learning of a foreign language. As well, these beliefs and attitudes were compared with the effect of socioeconomic status on education. Overall, the results of this study suggest that the reasons participants study a foreign language have more to do with socioeconomic status. Moreover, this trend becomes more pronounced in upper class and upper middle class students, whose success, failure, and motivation to learn a foreign language are influenced nearly by social class. The influence of socioeconomic status as a strong predictor of students' outcomes is prevalent. In fact, understanding language learners is a matter of examining a variety of evidence about their learning of language. Factors that promote foreign language learning are twofold: socioeconomic status and a genuine interest in foreign languages as a field of study. Factors that discourage foreign language learning and learning achievement are probably related to decreasing beliefs such as social and economic statuses, interests, and motivation. It is important to generate more positive attitudes in their students in spite of apparent evolution in students' beliefs and attitudes as they progress. There exist a wide variety of factors that might be expected to influence foreign language learning. One of the most important factors is the effect of socioeconomic factors on the language learning process that was explored in this study. Based on the findings of this study, learners' socioeconomic status has significant influence on language learning beliefs and academic outcomes.

\section{References}

Akhtar. Z., \&Niazi, H. K. (2011). The Relationship between socioeconomic status and learning achievement of students at secondary level. International Journal of Academic Research, 3(2).

Babikkoi, M. A., \& Binti-Abdul-Razak, N. Z. (2014). Implications of parents' socioeconomic status in the choice of English language learning strategies among Nigeria's secondary school students. English Language Teaching, 7(8). 
Baharudin, R., \& Luster, T. (1998). Factors related to the qualities of the environment and children's achievement. Journal of Family Issue, 19(4), 375-403. http://dx.doi.org/10.1177/019251398019004002

Barry, J. (2005). The effect of socioeconomic status on academic achievement. Department of Sociology, Wichita KS: Wichita State University.

Bartley, D. E. (1970). The importance of the attitude factor in language dropout: A preliminary investigation of group and sex differences. Foreign Language Annals, 3(3), 383-393. http://dx.doi.org/10.1111/j.1944-9720.1970.tb01292.x

Csizér, K., \& Dörnyei, Z. (2005). Language learners' motivational profiles and their motivated learning behavior. Language Learning, 55(4), 623-669. http://dx.doi.org/10.1111/j.0023-8333.2005.00319.x

Dörnyei, Z. (2005). The psychology of the language learner: Individual differences in second language acquisition. Lawrence N. J. Lawrence Erlbaum Associates.

Eamon, M. K. (2005). Social-demographic, school, neighborhood, and parenting influences on academic achievement of Latino young adolescent. Journal of youth and adolescence, 34(2), 163-174. http://dx.doi.org/10.1007/s10964-005-3214-x

Ewijk, \& Sleegers. (2010). The effect of peer SES on students Achievement: A meta-analysis. Journal of Educational Research Review, 5(2), 134-150.

Fan, W. (2011). Social influences, school motivation and gender differences: An application of the expectancy-value theory. Educ. Psychol. Rev., 31, 155-157. http://dx.doi.org/10.1080/01443410.2010.536525

Gardner, R. C. (1985). Social psychology aspects of second language learning: The role of attitudes a motivation. London: Arnold.

Goleman, D. (2009). What makes a leader? In D. Demers (Ed.), AHSC 230: Interpersonal communication and relationships (pp. 47-56). Montreal, Canada: Concordia University Bookstore.

Graham, S. J. (2006). A study of students' metacognitive beliefs about foreign language study and their impact on learning. Foreign Language Annals, 39, 296-309. http://dx.doi.org/10.1111/j.1944-9720.2006.tb02267.x

Hamid, M. O. (2011). Socioeconomic characteristics and English language achievement in Rural Bangladesh. Bangladesh e-Journal of Sociology, 8(2), 31-51.

Horwitz, E. K. (1987). Surveying student beliefs about language learning. In A. Wenden, \& J. Rubin (Eds.), Learner strategies in language learning (pp. 119-129). London: Prentice-Hall.

Horwitz, E. K. (1988). The beliefs about language learning of beginning university foreign language students. Modern Language Journal, 72, 283-293. http://dx.doi.org/10.1111/j.1540-4781.1988.tb04190.x

Jennes.W. H. (2002). Examing the effects of parental absence on the academic achievement of adolescent: The challenge of controlling for family income. Journal of Family and Economic Issues, 23(2).

Jernigan, C. G. (2001). The role of beliefs, attributions, and perceived goal attainment in students' motivation. In G. Bräuer (Ed.), Pedagogy of language learning in higher education (pp. 23-45). Westport, CT: Ablex

Kern, R. G. (1995). Students' beliefs and teachers' beliefs about language learning. Foreign Language Annals, 28, 71-92. http://dx.doi.org/10.1111/j.1944-9720.1995.tb00770.x

Knapp, M. S., \& Shields, P. M. (1990). Reconceiving Academic Institution for the Children of Poverty. Kappan, 71(10), 753-758.

Kormos, J., \& Kiddle, T. (2013). The role of socioeconomic factors in motivation to learn English as a foreign language: The case of Chile. System, 41, 399-412. http://dx.doi.org/10.1016/j.system.2013.03.006

Majoribanks, K. (1996). Family learning environments and students outcomes: A review. Journal of Comparative Family Studies, 27(2), 373-394.

Mattheoudakis, M., \& Alexiou, T. (2009). Early foreign language instruction in Greece: Socioeconomic factors and their effect on young learners' language development. In M. Nikolov (Ed.), The Age Factor and Early Language Learning. http://dx.doi.org/10.1515/9783110218282.227

Matthew, I. A. (2013). Provision of secondary education in Nigeria: Challenges and way forward. Journal of African Studies and Development, 5(1), 1-9. http://dx.doi.org/10.5897/JASD11.058

MCneal, R. B. (2001). Differntial effects of parental involvement on cognitive and behavioral outcomes by 
socioeconomic status. Economics, 30(2), 171-179. http://dx.doi.org/10.1016/S1053-5357 (00)00100-1

Miele, P. (1982). Suggestopedia: Easier learning the natural way. Sandy Spring, MD: Utopia Unlimited.

Mirza, M. Sh. (2001). Relationship of Socioeconomic Stats with Achievement. Journal Elementary Education, l(4), 18-24.

Ogunshola, F., \& Adewale, A. M. (2012). The Effects of Parental Socioeconomic Status on Academic Performance of Students in Selected Schools in EduLga of Kwara State Nigeria. International Journal of Academic Research in Business and Social Sciences, 2(7).

Rad, N. (2010). Evaluation of English Students' Beliefs about Learning English as Foreign Language: A Case of Kerman Azad University. Proceedings of ICT for Language Learning Conference 3rd Edition. Simonelli Editore.

Reed, S., \& Sautter, C. S. (1990). Children of poverty: The Status of 12 Million Young Americans. Phi Delta Kappan, 71(10), K1-K12.

Rifkin, B. (2000). Revisiting beliefs about foreign language learning. Foreign Language Annals, 33, 394-420. http://dx.doi.org/10.1111/j.1944-9720.2000.tb00621.x

Seyfried, Sh. F. (1998). Academic achievement of African American Preadolescent: The influence of teacher perception. American Journal of Community Psychology, 26(3). 381-402. http://dx.doi.org/10.1023/A:1022107120472

Sirin. S. R. (2005). SES and academic Achievement: A meta-Analytical review of Research. Review of Educational Research, 75 (31). 417-453. http://dx.doi.org/10.3102/00346543075003417

Skehan, P. (1989). Individual differences in second-language learning. New York: Edward Arnold

Spolsky, B. (1989). Conditions for second language learning: Introduction to a general theory. New York: Oxford University Press

Strevens, P. (1978). The nature of language teaching. In R. C. Richards (Ed.), Understanding second and foreign language learning: Issues and approaches (pp. 179-203). Rowley: Newbury House.

Vellymalay, S. (2012). Parental Involvement at Home: Analyzing the Influence of Parents' Socioeconomic Status. Studies in Sociology of Science, 3(1), 1-6. http://dx.doi.org/10.3968/j.sss.1923018420120301.2048

\section{Copyrights}

Copyright for this article is retained by the author(s), with first publication rights granted to the journal.

This is an open-access article distributed under the terms and conditions of the Creative Commons Attribution license (http://creativecommons.org/licenses/by/3.0/). 